\title{
RETIREMENT PROVISION ISSUES FOR EMPLOYEES AND EMPLOYERS
}

\author{
BY N. D. V. BODIE
}

(Synopsis of a paper presented to the Society on 28 March. 1989)

THIs paper deals with the alternatives faced by employers and employees in providing retirement pensions. It starts by considering the aspirations of employees and introduces the concept of a replacement ratio. This is the relationship between the salary received in the last year of employment and the level of pension required by the individual to maintain the same standard of living in the year following retirement, taking into account (a) tax, and (b) National Insurance and pension scheme contributions.

For the employer, the paper suggests that a 'target' employ'ee should be defined, in terms of length of service up to retirement and retained benefits from former employment, giving rise to a full career in terms of a period of pensionable service. By using this target employee, the employer can test various final salary benefit designs to see whether they satisfy the requirements of the necessary replacement ratio at different salary levels, and various other criteria. The paper demonstrates that schemes that are not integrated in some way with at least the Basic State pension, if not SERPS, fail by this measure. Alternative final salary scheme designs are considered, and again assessed against the various criteria previously established.

The next section considers defined contribution schemes. An example of the volatility of such arrangements, taking into account actual investment conditions between 1950 and 1987, is set out. The paper then goes on to use stochastic techniques to model the future volatility of defined contribution schemes. Even with a modified investment strategy, the results show that the variability of the outcomes is so great that, as a basic method of retirement provision, a serious misallocation of resources between different employees can arise purely as a result of the vagaries of investment markets. However, it is also pointed out that, at young ages, the extent of this volatility can be far outweighed by the magnitude of the pensions emerging by comparison with the benefits that would have arisen from a final salary scheme.

The final section is concerned with transfer values. Again using stochastic techniques, the paper illustrates the improvement that may be achieved by virtue of taking a transfer value that is calculated by reference to fixed interest yields and investing it in a personal pension which is largely invested in equities, which are expected to give a better overall real rate of return. Although the volatility of the personal pension is again greater than that of the final salary scheme deferred pension, the expected benefit at young ages is so much greater that the volatility becomes relatively insignificant. Indeed, taking a transfer value is shown to be capable of replacing much of the benefit lost by becoming an early leaver. 
The paper concludes that if the new forms of pension provision, with their associated uncertainties, become widespread, or if voluntary membership of pension schemes leads to a reduction in the provision made for retirement, an adequate safety net in the form of the Basic State pension is essential. The gradual erosion of National Insurance benefits, as evidenced by the deterioration of the State pension relative to earnings and the stated views of certain politicians, is viewed as highly regrettable.

\title{
THE ACTUARY'S ROLE IN DETERMINING PENSION FUND INVESTMENT STRATEGY
}

\author{
BY I. W. WOODS
}

(Synopsis of a paper presented to the Society on 11 April 1989)

THE paper outlines some of the practical issues currently facing actuaries in their current involvement in assisting clients define pension fund investment strategy.

Increasingly pension funds in the UK are considering the adoption of an investment strategy geared towards the particular circumstances of the fund and its sponsoring company.

The major reason for the move towards customized investment strategies has been the acceptance amongst corporate financial management of the importance which pension fund assets play in company finances.

Much of the work of the profession to date has involved reviewing past investment performance although little thought seems to have been applied in actually identifying whether or not the performance yardsticks being applied are really valid. Contrary to accepted business practice, companies have expended much of their energy reviewing the return on a substantial portion of their assets without a clear 'Business Plan' having been pre-determined.

The profession is ideally suited to assist in devising the long-term strategy of a pension fund although it is considered that conflicts of interest would arise between the actuarial adviser and the investment adviser should actuaries become involved in the short-term tactical asset allocation designed to take advantage of short-term movements in markets.

There should be a clear division of responsibilities between the liability-led nature of the advice on long-term strategy, which would be the responsibility of the actuary, and tactical asset allocation which would be the responsibility of the investment adviser.

It is suggested that the investment objectives for a pension fund should be based on the sponsoring company's business expectations for its pension fund. In this way, the objective of the pension fund's investment strategy can be directly related to the achievement of the company's strategic business objective for its pension fund. 